\title{
Update on the Serum Biomarkers and Genetic Factors Associated with Safety and Efficacy of rt-PA Treatment in Acute Stroke Patients
}

\author{
C. Nafría, I. Fernández-Cadenas, M. Mendioroz, S. Domingues-Montanari, \\ M. Hernández-Guillamón, J. Fernández-Morales, A. del Río-Espínola, D. Giralt, \\ L. Deu, P. Delgado, A. Rosell, and J. Montaner
}

Neurovascular Research Laboratory, Neurology and Medicine Departments, Vall d'Hebron Research Institute, Universitat Autònoma de Barcelona (VHIR-UAB), 08035 Barcelona, Spain

Correspondence should be addressed to J. Montaner,31862jmv@comb.cat

Received 16 June 2010; Revised 8 November 2010; Accepted 31 January 2011

Academic Editor: Eivind Berge

Copyright ( $) 2011$ C. Nafría et al. This is an open access article distributed under the Creative Commons Attribution License, which permits unrestricted use, distribution, and reproduction in any medium, provided the original work is properly cited.

An accurate understanding of the mechanisms underlying an individual's response to rt-PA treatment is critical to improve stroke patients' management. We thus reviewed the literature in order to identify biochemical and genetic factors that have been associated with safety and efficacy of rt-PA administration after stroke.

\section{Introduction}

Stroke is a complex disease and is considered to be the main cause of adult dependency and the third cause of death in industrialized countries. Ischemic stroke, defined by the obstruction of a blood vessel impairing cerebral blood flow, accounts for nearly $87 \%$ of all stroke cases. The only drug approved for the treatment of an acute ischemic stroke is alteplase or recombinant tissue plasminogen activator (rt$\mathrm{PA})$. The purpose of rt-PA administration is to provoke timely recanalization of the occluded vessel, which in turn restores blood flow in the ischemic area, and helps preserving the ischemic penumbra. rt-PA is a drug manufactured using recombinant technologies based on the tissue plasminogen activator ( $t-\mathrm{PA}$ ), an endogenous serine protease found in endothelial cells and involved in the breakdown of blood clots. This enzyme is responsible for the activation of plasminogen at an intravascular level and the catalyzation of its conversion into plasmin, which is the main protein implicated in clot lysis. Stroke guidelines recommend rt-PA administration no later than 4.5 hours after symptoms onset [1-6], based on the fact that, beyond this time point, adverse risks might outweigh benefits $[7,8]$.
Despite the great benefits of thrombolysis for stroke patients [8], only $14.3 \%$ of them are currently treated with this approach [9]. This low rate is mainly due to the fact that most patients arrive beyond the recommended time window for treatment to their to stroke center, but also to the adverse effects associated with rt-PA administration. The main concerns about rt-PA administration are its safety and efficacy. On one hand, the safety issue refers to the possible occurrence of severe hemorrhagic transformation (HT) after rt-PA infusion, which is a multifactorial phenomenon in which ischemic brain tissue converts into a hemorrhagic lesion with blood-vessel leakage, blood extravasation, and brain damage. There are several subtypes of HT, and they can be classified depending on their severity. Hemorrhagic infarction is usually considered as a relatively minor complication, while parenchymal hemorrhage $(\mathrm{PH})$ is considered to be the most serious case of HT, involving large hematomas and usually causing a massive effect. Symptomatic intracerebral hemorrhages (SICHs), such as most $\mathrm{PH}$, involve a neurological deterioration of four or more points on the National Institutes of Health Stroke Scale (NIHSS) score. They affect $2 \%$ to $6 \%$ of treated patients when evaluated at 36 hours and increase in frequency as late as the treatment 
is given [1-4]. SICHs result in poor clinical outcome and hamper efforts to extend the therapeutic window. On the other hand, the efficacy of rt-PA administration refers to the speed at which the cerebral artery can be recanalized, but also to the absence of reocclusion after a successful recanalization, both relating to neurological and functional outcome. Current knowledge on the occurrence of vessel recanalization shows that $30 \%$ to $36 \%$ of patients treated with rt-PA achieve complete recanalization, and up to $70 \%$ experience some degree of partial recanalization, although $33.8 \%$ to $40 \%$ of patients do not recanalize [10-13].

A better understanding of the biological and genetic factors associated with a patient's response to rt-PA is needed, because it might be useful in order to minimize the risk of SICH. Moreover, the identification of patients who arrived beyond the therapeutic time window, but present a low risk of complications and therefore might benefit from rt-PA treatment, might be useful, as could be the identification of patients presenting resistance to treatment. Indeed, these patients would probably not recanalize but could benefit from more invasive treatments such as intra-arterial rt-PA administration, mechanical thrombectomy, or the addition of sonothrombolyis to standard therapies. Finally, understanding the underlying mechanisms associated with the individual response to rt-PA would help physicians adjust drug doses accordingly. The aim of this study was thus to perform a review of the literature, to compile the results observed for blood biomarkers and genetic factors, which have been associated with efficacy and safety of rt-PA treatment in stroke patients.

\section{Biomarkers Associated with rt-PA Treatment}

A biomarker is a characteristic that is objectively measured and evaluated as an indicator of normal biologic processes, pathogenic processes, or pharmacologic responses to a therapeutic intervention [14]. The use of biomarkers is becoming a standard practice in some areas of medicine for decision-making processes, and some of them are already widely accepted. A good biomarker should ideally be specific and sensitive, detectable in samples readily available (urine, blood, hair or exhaled air), detectable rapidly and at low cost, should allow preventive measures and should be ethically accepted. Regarding thrombolytic therapy, plasma and serum biomarkers are the most commonly used in reported studies. Blood samples are usually collected before fibrinolytic therapy or during the hours immediately after rtPA infusion when temporal profiles want to be studied.

\subsection{Biomarkers Associated with Loss of Blood-Brain Integrity} and Hemorrhagic Transformation. HT, and specifically $\mathrm{SICH}$, is the most feared complication of rt-PA administration. It is thus really important to understand the mechanisms underlying this pathological condition. The National Institute of Neurological Disorders and Stroke (NINDS) study revealed that the risk of developing an SICH was $6 \%$ in rt-PA-treated patients compared to only $1 \%$ in the placebo group [1]; results have been later confirmed by other studies $[4,15]$. Over time, the therapeutic window has been established up to 4.5 hours after symptoms onset [57]. The advent of useful biomarkers to identify those patients with higher HT risk is crucial to safely widen that therapeutic window and allow more patients to benefit from this therapy.

Loss of integrity of the blood-brain barrier (BBB) resulting from ischemia and reperfusion is believed to be a precursor of HT and poor outcome after stroke. The $\mathrm{BBB}$ protects the brain against molecules and pathogens circulating through the blood stream. This specialized neurovascular interface comprises the endothelial tight junction, basal lamina, and astrocytic end feet. BBB leakage and blood constituents extravasation to the cerebral parenchyma are highly correlated with loss of basal lamina. Thus, maintaining basal lamina integrity is a key challenge to prevent hemorrhagic complications and brain damage induced by this phenomenon. Recent studies have implicated matrix metalloproteinases (MMPs) in this process, since they attack the basal lamina and later result in damage to the ultrastructure of the microvasculature. Peripheral blood neutrophils infiltration, which is closely related to the basal lamina collagen IV degradation and BBB breakdown, has been demonstrated in infarct areas [16]. Neutrophils use MMPs for their migration, and rt-PA has been shown to promote neutrophils degranulation and MMP-9 release in vitro [17].

MMPs are zinc-dependent endopeptidases that have a clear role in diverse cellular processes such as proliferation, apoptosis and tissue morphogenesis, and are also involved in most physiological processes involved in the extracellular matrix renewal. In addition to this role in repairing and remodelling, the presence of elevated levels of MMPs has been associated with tissue destruction in a wide variety of pathological processes. Some studies have implicated MMP2 and MMP-9 in cerebral ischemia [18-21]. When MMPs are overexpressed, they degrade substrates of the blood brain barrier, increase edema, inflammatory cell infiltration, and damage the brain parenchyma after stroke [22-24]. Moreover, high concentrations of MMP-9 $(>97 \mathrm{ng} / \mathrm{mL})$ in plasma before rt-PA treatment have been shown to predict HT occurrence (PH: $270.2 \pm 87.8 \mathrm{ng} / \mathrm{mL}$, non-HT: $126.3 \pm$ $127.5 \mathrm{ng} / \mathrm{mL} ; P=.047)[21,25]$. In fact, an almost linear relationship between the concentrations of MMPs and the severity of HT was observed $(\mathrm{HI}-1=37.4 \mathrm{ng} / \mathrm{mL}$; HI-2 = 111.0 ng $/ \mathrm{mL}$; PH-1 = $202.5 \mathrm{ng} / \mathrm{mL}$; PH-2 = $337.8 \mathrm{ng} / \mathrm{mL})$. In that study, a cut-off point for MMP-9 of $191.3 \mathrm{ng} / \mathrm{mL}$ had a sensitivity of $100 \%$ and a specificity of $78 \%$ to detect the presence of $\mathrm{PH}$ with a positive predictive value of $67 \%$ and a negative predictive value of 100\% [21] (Table 1).

Fibronectin, a component of the basement membrane, is an adhesive dimeric glycoprotein that promotes cell-tocell and cell-to-matrix interactions and is therefore involved in wound healing. High levels of cellular fibronectin (cFn) could be associated with endothelial damage. In fact, plasma c-Fn levels have been reported to be increased in patients with vascular injury [26]. A study suggested that cFn levels higher than $3.6 \mu \mathrm{g} / \mathrm{mL}$ in plasma, measured before rt-PA administration, could predict the development of HI2 and $\mathrm{PH}$ with a sensitivity and negative predictive value of $100 \%$ [27]. Later, a multicentre and prospective study found 
TABLE 1: Proteins associated with safety and efficacy of rt-PA.

\begin{tabular}{|c|c|c|c|c|c|c|}
\hline Protein & $n$ & Measurement & Concentration & OR $(95 \% \mathrm{CI})$ & Prediction & Reference \\
\hline \multicolumn{7}{|c|}{ Hemorrhagic transformation } \\
\hline MMP9 & 41 & Baseline & $\geq 140 \mathrm{ng} / \mathrm{mL}$ & $\begin{array}{l}9.62 \\
(1.31-70.26)\end{array}$ & HT & Montaner et al. [21] \\
\hline MMP9 & 250 & Baseline & $\geq 140 \mathrm{ng} / \mathrm{mL}$ & $\begin{array}{l}16(3 \text { to } 79) \\
P<.001\end{array}$ & HT & Castellanos et al. [25] \\
\hline c-Fn & 87 & Baseline & $\geq 3.6 \mu \mathrm{g} / \mathrm{mL}$ & $\begin{array}{l}2.1(1.3 \text { to } 3.4) \\
P=.002\end{array}$ & $\mathrm{HI}-2 / \mathrm{PH}$ & Castellanos et al. [27] \\
\hline MMP-9/c-Fn & 134 & Baseline & $\begin{array}{l}\text { MMP-9 } \geq \\
140 \mathrm{ng} / \mathrm{mL} / \mathrm{c}-\mathrm{Fn} \geq \\
3.6 \mu \mathrm{g} / \mathrm{mL}\end{array}$ & $\begin{array}{l}67(6.9-649) \\
P<.001\end{array}$ & HT & Castellanos et al. [28] \\
\hline VAP-1/SSAO & 141 & Baseline & $\begin{array}{l}\text { Activity }> \\
2.7 \mathrm{pmol} / \mathrm{min} \cdot \mathrm{mg}\end{array}$ & $\begin{array}{l}5.84 \\
(2.16-15.80) \\
P=.001\end{array}$ & $\mathrm{HT} / \mathrm{ND}$ & $\begin{array}{l}\text { Hernández-Guillamon } \\
\text { et al. [29] }\end{array}$ \\
\hline PAI-1/TAFI & 77 & Baseline & $\begin{array}{l}\text { TAFI }>180 \% \\
\text { PAI- } 1< \\
21.4 \mathrm{ng} / \mathrm{mL}\end{array}$ & $\begin{array}{l}12.9 ;(1.41 \text { to } \\
118.8) ; P=.02 \\
12.75(1.17 \text { to } \\
139.2) ; P=.04\end{array}$ & HT & Ribo et al. [30] \\
\hline APC & 119 & $\begin{array}{l}2 \mathrm{~h} \text { after } \\
\mathrm{rt}-\mathrm{PA}\end{array}$ & $\mathrm{APC}>176 \%$ & $\begin{array}{l}25.19 ; \\
(4.76-133.19) \\
P=.0001\end{array}$ & $\mathrm{PH}$ & Mendioroz et al. [31] \\
\hline S100B & 275 & Baseline & $\mathrm{S} 100 \mathrm{~B}>0.14$ & $\begin{array}{l}2.80(1.40 \text { to } \\
5.62) ; P=.004 \\
\end{array}$ & $\mathrm{HT}$ & Foerch et al. [32] \\
\hline \multicolumn{7}{|c|}{ Recanalization } \\
\hline PAI-1 & 77 & Baseline & PAI-1 > 34 ng/mL & & Poor Rec. & Ribo et al. [33] \\
\hline TAT & 85 & Post rt-PA & $<24 \mu \mathrm{g} / \mathrm{mL}$ & $\begin{array}{l}6 \text { hour: } 6.4 \\
(1.5-26.5) \\
P=.011\end{array}$ & Better rec. & $\begin{array}{l}\text { Fernandez-Cadenas } \\
\text { et al. [34] }\end{array}$ \\
\hline
\end{tabular}

HT: hemorrhagic transformation, PH: parenchymal hemorrhagic, ND: neurological deficit, Rec.: recanalization, sens: sensitivity, spec: specificity.

that baseline serum c-Fn and MMP-9 concentrations were significantly higher in patients with $\mathrm{HT}$ and $\mathrm{PH}[28]$. They also observed a sensitivity of $100 \%$, a specificity of $60 \%$, and positive and negative predictive values for $\mathrm{PH}$ using $\mathrm{c}-\mathrm{Fn}$ levels $\geq 3.6 \mu \mathrm{g} / \mathrm{mL}$ of $20 \%$ and $100 \%$, respectively, whereas corresponding values were $92 \%, 74 \%, 26 \%$, and $99 \%$ for MMP-9 levels $\geq 140 \mathrm{ng} / \mathrm{mL}$. When biomarkers were found above these cut-off points, the specificity increased up to $87 \%$, and the predicted positive value up to $47 \%$. The authors hypothesized that c-Fn could be a useful marker to identify the patients at greater risk of suffering an SICH (Table 1) [28].

These results suggest that MMPs and c-Fn are definitely involved in the occurrence of symptomatic bleedings, although they should be considered cautiously because their power on HT risk prediction is still unknown. The positive predictive value of these biomarkers might not be sufficiently high to be used in a clinical setting. Moreover, the sample size in these studies was small, thus requiring the study of HT, and not only symptomatic ones, which are the most relevant due to their fatal consequences. A large sample size is needed to study SICH due to its low prevalence in stroke patients. Therefore these results should be replicated by other groups, with larger sample size and bounded to SICH, before they could be generalized and useful for clinical practice. Assuming that markers that predict PH such as MMP-9 and fibronectin might be also interesting, we have recalculated the LR $(+)$ and $(-)$ for the article of Castellanos et al., considering a prevalence of the disease, that is, $\mathrm{PH}=8.96 \%$ ( $N=12 \mathrm{PH}, N=122$ non $\mathrm{PH})$, the PRE-TEST probability is then $8.96 \%$, with their data the Likelihood ratio +6.99 , and the Likelihood ratio -0.09 , so with that data the POSTTEST probability $=40 \%$ for the presence of $\mathrm{PH}$ and $1 \%$ for its absence. Therefore, even for the prediction of $\mathrm{PH}$ those markers are not useful to rule out patients from the treatment and probably they might only be used to rule in patients with a very low risk of bleedings.

One of the most recent and important findings in stroke biomarkers is the identification of vascular adhesion protein-1 (VAP-1) as a predictor of HT after rt-PA. VAP-1 is an ectoenzyme that belongs to the semicarbazide-sensitive amine oxidase (SSAO) family. It is expressed in endothelial cells, regulates leukocyte trafficking, including neutrophils and thus an association with BBB disruption was hypothesized. In addition, VAP-1 is associated with the extravasation under inflammatory conditions, and it increases ischemic brain injury, due to its function as an SSAO, by producing toxic metabolites [29]. Some studies have found abnormally high plasma VAP-1/SSAO activity in patients with some vascular or inflammatory conditions $[35,36]$. Another recent study showed that high levels of plasma VAP1/SSAO activity $(>2.7 \mathrm{pmol} / \mathrm{min} \cdot \mathrm{mg})$ measured before rt-PA treatment 
predicted the appearance of HT (OR (5.84 (2.16-15.80), $P=.001)$ ), the occurrence of PH (OR (11.18 (2.19-56.93), $P=.004)$ ) and neurological deterioration [29] (Table 1). VAP- $1 / \mathrm{SSAO}>2.7 \mathrm{pmol} / \mathrm{min} \cdot \mathrm{mg}$ had a sensitivity of $87.5 \%$, a specificity of $61.3 \%$, a positive predictive value of $62.26 \%$ and a negative one of $97.4 \%$. They also observed that delayed rt-PA cotreatment with the vap-1/SSAO inhibitor semicarbazide, in an animal model, reduced the infarct volume $(8.73 \%(0-50 \%)$ semicarbazide group versus $35.46 \%$ $(8.43-45.83 \%)$ saline group; $P=.036)$ and the presence of bleedings [ $18 \%$ versus $43 \%$, resp.), so they suggested that the use of SSAO inhibitors could be an adjuvant treatment to rt-PA, blocking the leukocyte migration effect that might prevent rt-PA-induced neutrophil degranulation. A potentially valuable strategy to study $\mathrm{SICH}$ prevention mechanisms would be to target the molecules involved in the infiltration of neutrophils in the ischemic areas such as VAP1/SSAO. Nevertheless, more research should be performed to validate these results. Larger patients groups are needed in order to study the risk of SICH and clinical trials should be performed to test this or other adjuvant therapies in the future. On the other hand, the positive predictive value for VAP-1/SSAO was higher than those observed with MMP9 and c-Fn $(62.26 \%$ versus $26 \%$ and $20 \%$, resp.) which indicates that VAP-1/SSAO measured before rt-PA would be a better candidate to predict $\mathrm{PH}$. Maybe in the future the combination of several biomarkers would be the solution to increase the predictive value and to be used in daily clinical practice.

Interestingly, VAP-1/SSAO is also linked to oxidative stress, and we have recently described that some oxidative stress related markers such as malondialdehyde (MDA) are indeed related to the appearance of HT following tPA treatment [37].

\subsection{Biomarkers Associated with Fibrinolysis and Coagulation} Homeostasis. Plasminogen activator inhibitor-1 (PAI-1) is the main endogenous inhibitor of rt-PA. It binds directly to rt-PA and inhibits its fibrinolytic action by a stechiometric action $1: 1$. PAI-1 has been consistently associated with acute stroke [38-40] and with other cerebrovascular diseases $[41,42]$. Thrombin-activable fibrinolysis inhibitor (TAFI) is an indirect fibrinolysis inhibitor. It is activated by the complex thrombin/thrombomodulin or plasmin, which has an inhibitory effect on fibrinolytic processes. TAFI cleaves n-terminal lysine residues off fibrin (it may possibly also split from fibrin monomers) and thereby prevents rt-PA and plasminogen bind. Elevated TAFI levels have been reported as a risk factor for stroke [43, 44]. Regarding thrombolytic treatment, some in vitro studies and animal models have shown that the inhibition of TAFI accelerates clot dissolution by rt-PA [45-47]. Ribo et al. found that levels of PAI-1 < $21.4 \mathrm{ng} / \mathrm{mL}$ and TAFI levels $>180 \%$ in plasma, measured before rt-PA administration and determined by enzymelinked immunosorbent assays (ELISAs), predicted SICH occurrence $(75 \%$ positive predictive value, predictive value negative 97.6\%) [30] (Table 1). However, the sample size studied was small, and there are no other studies that support these results.

Recently, the activated protein C (APC), a plasma serine protease with an anticoagulant activity and a wide range of cytoprotective functions [48-51], has shown to prevent bleeding induced by rt-PA in vivo in animal models and to reduce the expression of MMP-9 in human brain endothelial cells in vitro [52]. Thus, it was suggested that the coadministration of this protein with rt-PA could be useful to expand the therapeutic window of rt-PA [53]. However, since the APC is a protein with an anticoagulant action, ischemic stroke patients treated with this drug could suffer bleeding complications [54]. Recently, an association of APC concentration with bleeding complications and mortality after rt-PA treatment has been revealed. Two hours after starting treatment, APC levels over $176 \%$ predicted $\mathrm{PH}$ while APC levels over $157 \%$ predicted mortality [31] (Table 1). In this study, the authors pointed out that high APC levels could be a cause or even a consequence of posterior HT occurrence. However, APC is not a useful biomarker since its association with HT was observed 2 hours after and not before rt-PA administration.

\subsection{Biomarkers Associated with Recanalization. Regarding} treatment efficacy, several molecules have been associated with the revascularization of brain vessels or recanalization. The most important are associated with the fibrinolysis and coagulation systems. An increase in PAI-1 activity has been reported in stroke patients, as compared with controls $(11.6 \mathrm{U} / \mathrm{mL}$ versus $8.8 \mathrm{U} / \mathrm{mL}, P<.0001)$ [40], and patients with higher concentrations of PAI-1 in plasma (PAI-1 > $34 \mathrm{ng} / \mathrm{mL}$ ), previous to rt-PA administration, showed poor recanalization rates [33]. The main endogenous inhibitor of plasmin, which is a key enzyme for fibrinolysis, the alpha2-antiplasmin, was also found to be involved, albeit with contradictory results, in recanalization after rt-PA. A study showed that patients who did not recanalize within the six first hours after fibrinolytic treatment had lower plasma levels of alpha-2-antiplamin than those who did $(96.5 \%$ versus $87.5 \%$, resp., $P=.023$ ) and also for functional TAFI (91.7\% versus $104.4 \%, P=.039$ ) [58]. But a later study of the same group found no association [59]. The ThrombinAntithrombin (TAT) complex can be used as an indirect measure of thrombin concentration in plasma, which is considered to be the central enzyme of the coagulation cascade. Thrombin exerts opposite effects and is a key factor in the regulation of haemostasis [60]. A report described how high levels of TAT in plasma measured 24 hours after rt-PA infusion predicted poor outcome three months after an ischemic stroke [61]. Moreover, a recent study showed that low baseline plasmatic levels of TAT were associated with better rates of complete artery recanalization one hour after fibrinolytic treatment $(\mathrm{OR}=24.8$ IC 95\% 1.4-434.8; $P=.028)$, as well as 2 hours ( $\mathrm{OR}=6.3$ IC 95\% $1.5-27$; $P=.014)$ and 6 hours $(\mathrm{OR}=6.4$ IC 95\% 1.5-26.5; $P=$ .011) [34] (Table 1). This study did not confirm a significant association between TAT levels and mortality at 3 months, but the mechanism involved in this poor outcome could 
TABLE 2: Polymorphisms and genes associated with rt-PA safety or efficacy.

\begin{tabular}{|c|c|c|c|c|c|c|}
\hline Polymorphism/Gene & Measure & $\%$ & $P$-value & OR $(95 \% \mathrm{CI})$ & Prediction & Reference \\
\hline \multicolumn{7}{|c|}{ Hemorrhagic transformation } \\
\hline Val34Leu FXIII gene & DNA & $\begin{array}{l}\text { leu: } 11.9 \% \text { severe } \\
\text { HT Val: } 3.4 \% \text {; }\end{array}$ & $P<.05$ & $\begin{array}{c}2.95(1.07 \text { to } 8.11) ; \\
P=.035\end{array}$ & $\mathrm{SICH}$ & $\begin{array}{l}\text { González-Conejero et al. } \\
\text { [55] }\end{array}$ \\
\hline \multicolumn{7}{|c|}{ Recanalization } \\
\hline I/D ACE gene & DNA & $\begin{array}{l}\mathrm{DD}=69.2 \%, \mathrm{ID} \\
+\mathrm{II}=31.6 \% ;\end{array}$ & $P=.002$ & $4.3(1.35-13.49)$ & Good Rec. & $\begin{array}{l}\text { Fernandez-Cadenas } \\
\text { et al. [56] }\end{array}$ \\
\hline Thr325Ile TAFI gene & DNA & $\begin{array}{l}\text { Thr/Thr: } 42 \% \text {, } \\
\text { Thr/Ile: } 48 \% \text {, } \\
\text { Ile/Ile: } 13.3 \% \text {; }\end{array}$ & $P<.05$ & N/A & Low rec. & $\begin{array}{l}\text { Fernandez-Cadenas } \\
\text { et al. [57] }\end{array}$ \\
\hline $\begin{array}{l}\text { Thr325Ile }(\mathrm{Hm})+\mathrm{G} 4 \\
\text { PAI-1 TAFI gene }\end{array}$ & DNA & $\begin{array}{l}\text { Ile/Ile + 4G: } \\
\text { 7.1\%; other: } \\
45.9 \% \text {; }\end{array}$ & $P<.05$ & $\begin{array}{c}11.06(1.36-89.8) \\
P=.025\end{array}$ & Low rec. & $\begin{array}{l}\text { Fernandez-Cadenas } \\
\text { et al. [57] }\end{array}$ \\
\hline
\end{tabular}

Polymorphisms and genes associated with rt-PA safety or efficacy. HT: hemorrhagic transformation. Rec.: recanalization.

be the absence of recanalization rather than the increase in HT rates, since it is well known that the absence of vessel reopening is associated with worse neurological outcome and mortality [62].

2.4. Biomarkers with Other Modes of Action. Finally, S100B, a calcium-binding protein, has been reported to be a serum marker of BBB dysfunction [63]. It has regulatory functions at an intracellular and extracellular level, related to cell migration and proliferation, apoptosis inhibition, and cell differentiation, has been associated with HT occurrence. S100B is important in the activation of astrocytes in the course of brain damage and neurodegenerative processes [64]. It has been associated with some cerebrovascular diseases, such as hypoxic-ischemic brain injury or intracerebral hemorrhage. High concentrations of this protein $(\mathrm{S} 100 \mathrm{~B}>0.21 \mu \mathrm{g} / \mathrm{L})$ are associated with an increased risk of HT after thrombolytic therapy (2.80 (1.40 to $5.62 ; P=.004))$ [32] (Table 1$)$. They found that a cut-off point of $0.23 \mu \mathrm{g} / \mathrm{L}$ provided a specificity of 0.82 for prediction of $\mathrm{PH}-2$ (positive predictive value of $12 \%$, a negative predictive value of $97 \%, \mathrm{AUC}=0.661$, $P=.01)$, but the clinical usefulness of this biomarker is not clear due to its low positive predictive value. In any case, $\mathrm{S} 100 \mathrm{~B}$ seems to reflect $\mathrm{BBB}$ disruption in the acute phase of ischemic stroke, although it is not specific enough to show $\mathrm{BBB}$ leakage extension and reflect, therefore, the degree of HT.

Also, urinary micro- and macroalbuminuria, that indicates dysfunction of vascular endothelium, has been reported to independently predict hemorrhagic transformation in acute ischemic stroke and might therefore be added to the list of pathways involved in the process of HT [65].

\section{Pharmacogenetics of rt-PA}

Pharmacogenetics is a discipline that studies the response of an organism, depending on its genetic background, to a given drug. It has emerged as a strong tool to individualize therapies with the purpose of preidentifying patients who will better respond to a given treatment or to choose the most appropriate dose or type of drug needed for each patient [66]. Many efforts are being made to identify genetic biomarkers that could be used to predict the response of an individual patient to fibrinolytic therapy.

3.1. Genetic Predictors of Hemorrhagic Transformation. Factor XIII (FXIII) is a coagulation factor implicated in the coagulation cascade and its main role is to cross-link fibrin. FXIII is activated by thrombin and is responsible for the clot stabilization, for incorporating proteins such as fibronectin, thrombospondin and antifibrinolytic protein alpha 2antiplasmin, thus making the thrombus relatively more resistant to fibrinolysis $[67,68]$. The Val34Leu polymorphism of the FXIII gene has been extensively studied in several vascular pathologies such as myocardial infarction, venous thromboembolism and ischemic and hemorrhagic stroke, but with contradictory results. Some reports have shown that the Leu allele is a protective factor for cardiovascular diseases $[69,70]$, while others have not confirmed this association $[71,72]$. Focusing on stroke, results are also contradictory. Some studies indicate that the Leu allele is a risk factor for hemorrhagic and ischemic stroke [73] whilst others could not observe this effect $[74,75]$. Regarding thrombolytic therapy, patients with the Val/Val genotype presented lower incidence of SICH than Leu allele carriers. Similarly, homozygous $\mathrm{Val} / \mathrm{Val}$ carriers showed lower mortality rates. Moreover, Val/Val patients with fibrinogen concentrations lower than $3.6 \mathrm{~g} / \mathrm{L}$ presented mortality rates of $8.8 \%$ against $35.7 \%$ for the rest of patients. When the neurological deficit was evaluated, patients carrying the Leu allele plus fibrinogen concentrations $\geq 3.6 \mathrm{~g} / \mathrm{L}$ obtained the highest values on the NIHSS, indicating worse neurological status [55] (Table 2). Currently, the Val34Leu polymorphism is the only genetic variation associated with HT; however new studies with an increased sample size are required to confirm these results.

Regarding MMP-9, the C1562T polymorphism, which is located in the promoter region of the MMP-9 gene, has been described as a factor that could modify MMP9 levels in vitro. In this study, the $\mathrm{T}$ allele conferred an increase in MMP-9 concentrations due to increased MMP-9 promoter activity [76]. Also, the $\mathrm{T}$ allele has been associated with 
increased concentrations of MMP-9 on different pathologies like coronary artery disease [77], arterial stiffness of large vessels [78] and abdominal aortic aneurysm [79]. Since MMP-9 levels are associated with HT appearance, it was hypothesized that this allele could be associated with the development of this complication in vivo. However, to date, no association has been demonstrated between this polymorphism and MMP concentrations or hemorrhagic complications in humans, probably because this mutation is not functional in response to cerebral ischemia in vivo or because of the small sample size [80].

3.2. Genetic Predictors of Recanalization. The angiotensin converting enzyme (ACE) is an enzyme that belongs to the renin-angiotensin and the kallikrein-kinin systems. ACE plays an important role in hypertension and vasoconstriction by catalysing the transformation of angiotensin I into angiotensin II [81]. Several studies have associated the inhibition of the renin-angiotensin-aldesterone system with a lower incidence of ischemic stroke and vascular recurrence (Heart Outcome Prevention Evaluation (HOPE), Losartan Intervention for Endpoint Reduction in Hypertension Study (LIFE) and Acute Candesartan Cilexetil Evaluation in Stroke Survivors (AACESS)). An insertion/deletion (I/D) polymorphism in intron 16 of the gene influences serum enzyme levels [82]. The D allele homozygous present higher levels of ACE in serum, and I allele carriers showed lower levels. The gene has also been linked to PAI-1, in the sense that the deletion allele was associated with elevated levels of PAI-1 $[83,84]$, which in turn was associated with recanalization resistance [61], hence its antifibrinolytic behavior. On the other hand, the $\mathrm{D}$ allele has also been associated with lower activity of coagulation factors X and VII [85] and with low levels of fibrinogen [86], adding an antithrombotic activity. More recently and accordingly to that, a study showed that the DD genotype was strongly associated with better recanalization rates in ischemic stroke treated with rt-PA $(\mathrm{DD}=69.2 \%, \mathrm{ID}+\mathrm{II}=31.6 \%, P=.002$ at $1 \mathrm{~h} ; \mathrm{DD}=91.3 \%$, $\mathrm{ID}+\mathrm{II}=51 \%, P=.001$ at $6 \mathrm{~h} ; \mathrm{DD}=100 \%$, ID $+\mathrm{II}=$ $72.3 \%, P=.003$ at $24 \mathrm{~h}$ post-t-PA administration) without increasing the odds of bleeding $(P=.237)$ [56] (Table 2). However, the authors failed to demonstrate an association of the D allele with PAI-1 or FX and FVII activity.

Regarding TAFI, one of the indirect inhibitors of fibrinolysis, a polymorphism in the coding region of the gene (C1040T) resulting in the Thr325Ile substitution, has been associated with a $60 \%$ increase of TAFI activity $[87,88]$, associated with its antifibrinolytic effect. In addition, a study observed that the presence of the Thr/Ile polymorphism was associated with lower recanalization rates in combination with the PAI-1 4G/5G polymorphism [57]. The $4 \mathrm{G} / 5 \mathrm{G}$ polymorphism is located in the promoter region of the PAI1 gene. Classically, the $4 \mathrm{G}$ allele has been associated with high levels of PAI-1 in plasma $[83,89]$. A large number of association studies have focused on stroke and cardiovascular events with contradictory results [40, 90-92]. Referring to the efficacy of thrombolytic agents, it has been reported that the combination of $4 \mathrm{G}$ allele of PAI-1 gene and Ile/Ile genotype of TAFI increased the risk of recanalization resistance (OR 11.1 (95\% CI 1.4-89.8, $P=.025$ ) [57] (Table 2). The sample size of pharmacogenetic studies is often small. Similarly to biomarkers studies, replications of the significant results obtained should be performed to elucidate the role of these SNPs in rt-PA safety and efficacy. However, it seems that there is a genetic susceptibility to rt-PA response since several studies have identified different polymorphisms associated with rt-PA response. The implementation of these findings in the clinical practice will be difficult due to the lack of fast polymorphisms detection systems.

\section{Discussion}

Many efforts have been made to identify the biological and genetic markers that can predict SICH and successful recanalization after rt-PA infusion, but all the studies present some methodological issues. Most of them used small sample sizes, which makes it difficult to study SICH (due to its low prevalence), so they analyzed all types of HT. More studies focusing only on SICH are needed. Hence, larger samples sizes are needed to replicate and validate these results. Over all, biomarkers studies published to date should be regarded as preliminary studies, since they did not elucidate the clinical relevance of any single marker or a panel of different markers. Most of these studies were performed with small samples sizes and the positive predictive values were too low in most of them. VAP-1/SSAO seems to be a promising biomarker due to its moderately acceptable positive predictive value. Unfortunately, there is no reliable risk indicator enabling these high-risk patients to be sufficiently identified yet. The diagnostic accuracy of biomarkers investigated to date (i.e., matrix metalloproteinase-9, fibronectin, S100B, VAP-1/SSAO) does not appear to be good enough to function as a reliable test in acute stroke management.

Another important issue is how to discern whether the markers found are related to the HT or to the severity of stroke itself. MRI studies performed before rt-PA administration might help us to elucidate this, by using the infarct volume before fibrinolytic treatment and the basal NIHSS as variables in the statistical analysis, and also evaluating the presence of specific BBB leakage signs such as hyperintense acute reperfusion injury as a marker (HARM) [93],

Also further research must be done attempting to find new genes and polymorphisms that explain occurrence of complication or poor recanalization in order to improve therapies given to the patients. Findings should also be replicated and validated in different and larger populations.

A more meaningful understanding of gene expression can be achieved through massive techniques as microarrays or genome wide association studies (GWASs), since new genes and their products could be discovered. It is clear, however, that all this information although essential, is not sufficient. The function of most genes is still unknown, and proteomic studies are now attempting to fill this need. The ultimate phenotype of cells, organs, and organisms is reflected in their instantaneous proteomic profile. Changes in human states of health are the result of changes in the proteomes 
of individual patient overtime and in response to endogenous and/or external stimuli. However, the advent of novel approaches and large-scale technologies to investigate the complexity of human disease promises to shed new light on the pathogenesis of a broad range of diseases, including stroke and stroke pharmacogenomics. In fact, a very recent report have shown, for the very first time, changes in protein profiles in human stroke brain samples compared with controls which led to the advent of new proteins that should be studied in depth to test whether they can be considered good biomarkers of stroke [94]. Thus it seems clears that a functional proteomic approach would facilitate an understanding of signaling pathways in stroke and treatment response that will allow the long-awaited personalized therapy and also could help to identify new lists of proteins that could be implicated in rt-PA response and therefore could be considered and analyzed further as therapeutic targets or novel biomarkers for rt-PA response.

\section{Conclusion}

Despite recent great advances in basic research considering the safety and efficacy of rt-PA treatment in stroke patients, it is still difficult to translate the findings observed to the clinical practice, and there is still a long way to go before these findings can be implemented in hospital settings. Current technology allows the quantitative detection of proteins in several minutes, but the detection of risk polymorphisms in a timely manner after the patient's arrival to the hospital is still not possible nowadays. Efforts should thus be made in this direction, in order to allow rapid screening of the patients, combining genetic, biochemical and clinical factors, thus improving the predictive value of these tools and guiding the clinician's choice for treatment.

\section{References}

[1] National Institute of Neurological Disorders and Stroke rt-PA Stroke Study Group, "Tissue plasminogen activator for acute ischemic stroke," The New England Journal of Medicine, vol. 333, pp. 1581-1587, 1995.

[2] N. Wahlgren, N. Ahmed, A. Davalos et al., "Thrombolysis with alteplase for acute ischaemic stroke in the Safe Implementation of Thrombolysis in Stroke-Monitoring Study (SITSMOST): an observational study," Lancet, vol. 369, no. 9558, pp. 275-282, 2007.

[3] N. Wahlgren, N. Ahmed, N. Eriksson et al., "Multivariable analysis of outcome predictors and adjustment of main outcome results to baseline data profile in randomized controlled trials: safe implementation of thrombolysis in StrokeMOnitoring STudy (SITS-MOST)," Stroke, vol. 39, no. 12, pp. 3316-3322, 2008.

[4] J. M. Wardlaw, G. Zoppo, T. Yamaguchi, and E. Berge, "Thrombolysis for acute ischaemic stroke," Cochrane Database of Systematic Reviews, no. 3, article CD000213, 2003.

[5] The ATLANTIS, ECASS, and NINDS rt-PA Study Group Investigators, "Association of outcome with early stroke treatment: pooled analysis of ATLANTIS, ECASS, and NINDS rt-PA stroke trials," Lancet, vol. 363, pp. 768-774, 2004.
[6] M. G. Lansberg, E. Bluhmki, and V. N. Thijs, "Efficacy and safety of tissue plasminogen activator 3 to 4.5 hours after acute ischemic stroke: a metaanalysis," Stroke, vol. 40, no. 7, pp. 2438-2441, 2009.

[7] K. R. Lees, E. Bluhmki, R. von Kummer et al., "Time to treatment with intravenous alteplase and outcome in stroke: an updated pooled analysis of ECASS, ATLANTIS, NINDS, and EPITHET trials," The Lancet, vol. 375, no. 9727, pp. 1695$1703,2010$.

[8] J. M. Wardlaw, P. A. G. Sandercock, and E. Berge, "Thrombolytic therapy with recombinant tissue plasminogen activator for acute ischemic stroke: where do we go from here? A cumulative meta-analysis," Stroke, vol. 34, no. 6, pp. 14371442, 2003.

[9] J. H. Lichtman, E. Watanabe, N. B. Allen, S. B. Jones, J. Dostal, and L. B. Goldstein, "Hospital arrival time and intravenous tpa use in us academic medical centers, 2001-2004," Stroke, vol. 40, no. 12, pp. 3845-3850, 2009.

[10] A. V. Alexandrov, A. M. Demchuk, R. A. Felberg et al., "High rate of complete recanalization and dramatic clinical recovery during tPA infusion when continuously monitored with 2$\mathrm{MHz}$ transcranial Doppler monitoring," Stroke, vol. 31, no. 3, pp. 610-614, 2000.

[11] C. A. Molina, A. V. Alexandrov, A. M. Demchuk, M. Saqqur, K. Uchino, and J. Alvarez-Sabín, "Improving the predictive accuracy of recanalization on stroke outcome in patients treated with tissue plasminogen activator," Stroke, vol. 35, no. 1, pp. 151-156, 2004.

[12] I. Christou, A. V. Alexandrov, W. S. Burgin et al., "Timing of recanalization after tissue plasminogen activator therapy determined by transcranial Doppler correlates with clinical recovery from ischemic stroke," Stroke, vol. 31, no. 8, pp. 1812$1816,2000$.

[13] A. M. Demchuk, W. S. Burgin, I. Christou et al., "Thrombolysis in Brain Ischemia (TIBI) transcranial Doppler flow grades predict clinical severity, early recovery, and mortality in patients treated with intravenous tissue plasminogen activator," Stroke, vol. 32, no. 1, pp. 89-93, 2001.

[14] A. J. Atkinson, W. A. Colburn, V. G. DeGruttola et al., "Biomarkers and surrogate endpoints: preferred definitions and conceptual framework," Clinical Pharmacology and Therapeutics, vol. 69, no. 3, pp. 89-95, 2001.

[15] G. D. Graham, "Tissue plasminogen activator for acute ischemic stroke in clinical practice: a meta-analysis of safety data," Stroke, vol. 34, no. 12, pp. 2847-2850, 2003.

[16] A. Rosell, E. Cuadrado, A. Ortega-Aznar, M. HernandezGuillamon, E. H. Lo, and J. Montaner, "MMP-9-positive neutrophil infiltration is associated to blood-brain barrier breakdown and basal lamina type IV collagen degradation during hemorrhagic transformation after human ischemic stroke," Stroke, vol. 39, no. 4, pp. 1121-1126, 2008.

[17] E. Cuadrado, L. Ortega, M. Hernandez-Guillamon et al., "Tissue plasminogen activator (t-PA) promotes neutrophil degranulation and MMP-9 release," Journal of Leukocyte Biology, vol. 84, no. 1, pp. 207-214, 2008.

[18] G. A. Rosenberg, M. Navratil, F. Barone, and G. Feuerstein, "Proteolytic cascade enzymes increase in focal cerebral ischemia in rat," Journal of Cerebral Blood Flow and Metabolism, vol. 16, no. 3, pp. 360-366, 1996.

[19] A. M. Romanic, R. F. White, A. J. Arleth, E. H. Ohlstein, and F. C. Barone, "Matrix metalloproteinase expression increases 
after cerebral focal ischemia in rats: inhibition of matrix metalloproteinase-9 reduces infarct size," Stroke, vol. 29, no. 5, pp. 1020-1030, 1998.

[20] M. Fujimura, Y. Gasche, Y. Morita-Fujimura, J. Massengale, M. Kawase, and P. H. Chan, "Early appearance of activated matrix metalloproteinase- 9 and blood-brain barrier disruption in mice after focal cerebral ischemia and reperfusion," Brain Research, vol. 842, no. 1, pp. 92-100, 1999.

[21] J. Montaner, C. A. Molina, J. Monasterio et al., "Matrix metalloproteinase- 9 pretreatment level predicts intracranial hemorrhagic complications after thrombolysis in human stroke," Circulation, vol. 107, no. 4, pp. 598-603, 2003.

[22] G. A. Rosenberg, "Matrix metalloproteinases in neuroinflammation," Glia, vol. 39, no. 3, pp. 279-291, 2002.

[23] E. H. Lo, T. Dalkara, and M. A. Moskowitz, "Mechanisms, challenges and opportunities in stroke," Nature Reviews Neuroscience, vol. 4, no. 5, pp. 399-415, 2003.

[24] E. H. Lo, X. Wang, and M. L. Cuzner, "Extracellular proteolysis in brain injury and inflammation: role for plasminogen activators and matrix metalloproteinases," Journal of Neuroscience Research, vol. 69, no. 1, pp. 1-9, 2002.

[25] M. Castellanos, R. Leira, J. Serena et al., "Plasma metalloproteinase-9 concentration predicts hemorrhagic transformation in acute ischemic stroke," Stroke, vol. 34, no. 1, pp. 40-45, 2003.

[26] J. H. Peters, R. J. Maunder, A. D. Woolf, C. G. Cochrane, and M. H. Ginsberg, "Elevated plasma levels of ED1+ ("cellular") fibronectin in patients with vascular injury," Journal of Laboratory and Clinical Medicine, vol. 113, no. 5, pp. 586-597, 1989.

[27] M. Castellanos, R. Leira, J. Serena et al., "Plasma cellularfibronectin concentration predicts hemorrhagic transformation after thrombolytic therapy in acute ischemic stroke," Stroke, vol. 35, no. 7, pp. 1671-1676, 2004.

[28] M. Castellanos, T. Sobrino, M. Millan et al., "Serum cellular fibronectin and matrix metalloproteinase- 9 as screening biomarkers for the prediction of parenchymal hematoma after thrombolytic therapy in acute ischemic stroke: a multicenter confirmatory study," Stroke, vol. 38, no. 6, pp. 1855-1859, 2007.

[29] M. Hernandez-Guillamon, L. Garcia-Bonilla, M. Solé et al., "Plasma VAP-1/SSAO activity predicts intracranial hemorrhages and adverse neurological outcome after tissue plasminogen activator treatment in stroke," Stroke, vol. 41, no. 7, pp. 1528-1535, 2010.

[30] M. Ribo, J. Montaner, C. A. Molina et al., "Admission fibrinolytic profile is associated with symptomatic hemorrhagic transformation in stroke patients treated with tissue plasminogen activator," Stroke, vol. 35, no. 9, pp. 2123-2127, 2004.

[31] M. Mendioroz, I. Fernandez-Cadenas, J. Alvarez-Sabín et al., "Endogenous activated protein $\mathrm{C}$ predicts hemorrhagic transformation and mortality after tissue plasminogen activator treatment in stroke patients," Cerebrovascular Diseases, vol. 28, no. 2, pp. 143-150, 2009.

[32] C. Foerch, M. T. Wunderlich, F. Dvorak et al., "Elevated serum S100B levels indicate a higher risk of hemorrhagic transformation after thrombolytic therapy in acute stroke," Stroke, vol. 38, no. 9, pp. 2491-2495, 2007.

[33] M. Ribo, J. Montaner, C. A. Molina, J. F. Arenillas, E. Santamarina, and J. Alvarez-Sabín, "Admission fibrinolytic profile predicts clot lysis resistance in stroke patients treated with tissue plasminogen activator," Thrombosis and Haemostasis, vol. 91, no. 6, pp. 1146-1151, 2004.

[34] I. Fernandez-Cadenas, M. Mendioroz, J. Munuera et al., "Lower concentrations of thrombin-antithrombin complex (TAT) correlate to higher recanalisation rates among ischaemic stroke patients treated with t-PA," Thrombosis and Haemostasis, vol. 102, no. 4, pp. 759-764, 2009.

[35] F. Boomsma, D. J. Van Veldhuisen, P. J. De Kam et al., "Plasma semicarbazide-sensitive amine oxidase is elevated in patients with congestive heart failure," Cardiovascular Research, vol. 33, no. 2, pp. 387-391, 1997.

[36] F. Boomsma, A. H. Van Den Meiracker, S. Winkel et al., "Circulating semicarbazide-sensitive amine oxidase is raised both in type I (insulin-dependent), in type II (non-insulindependent) diabetes mellitus and even in childhood type I diabetes at first clinical diagnosis," Diabetologia, vol. 42, no. 2, pp. 233-237, 1999.

[37] C. Domínguez, P. Delgado, A. Vilches et al., "Oxidative stress after thrombolysis-induced reperfusion in human stroke," Stroke, vol. 41, no. 4, pp. 653-660, 2010.

[38] M. Margaglione, G. Di Minno, E. Grandone et al., "Abnormally high circulation levels of tissue plasminogen activator and plasminogen activator inhibitor-1 in patients with a history of ischemic stroke," Arteriosclerosis and Thrombosis, vol. 14, no. 11, pp. 1741-1745, 1994.

[39] A. Lindgren, C. Lindoff, B. Norrving, B. Åstedt, and B. B. Johansson, "Tissue plasminogen activator and plasminogen activator inhibitor-1 in stroke patients," Stroke, vol. 27, no. 6, pp. 1066-1071, 1996.

[40] A. J. Catto, A. M. Carter, M. Stickland, J. M. Bamford, J. A. Davies, and P. J. Grant, "Plasminogen activator inhibitor-1 (PAI-1) 4G/5G promoter polymorphism and levels in subjects with cerebrovascular disease," Thrombosis and Haemostasis, vol. 77, no. 4, pp. 730-734, 1997.

[41] A. Hamsten, G. Walldius, and A. Szamosi, "Plasminogen activator inhibitor in plasma: risk factor for recurrent myocardial infarction," Lancet, vol. 2, no. 8549, pp. 3-9, 1987.

[42] J. Schneiderman, M. S. Sawdey, M. R. Keeton et al., "Increased type 1 plasminogen activator inhibitor gene expression in atherosclerotic human arteries," Proceedings of the National Academy of Sciences of the United States of America, vol. 89, no. 15, pp. 6998-7002, 1992.

[43] J. Montaner, M. Ribó, J. Monasterio, C. A. Molina, and J. Alvarez-Sabín, "Thrombin-activable fibrinolysis inhibitor levels in the acute phase of ischemic stroke," Stroke, vol. 34, no. 4, pp. 1038-1040, 2003.

[44] A. Santamaría, A. Oliver, M. Borrell et al., "Risk of ischemic stroke associated with functional thrombin-activatable fibrinolysis inhibitor plasma levels," Stroke, vol. 34, no. 10, pp. 2387-2391, 2003.

[45] L. O. Mosnier, P. A. KR. Von Dem Borne, J. C. M. Meijers, and B. N. Bouma, "Plasma TAFI levels influence the clot lysis time in healthy individuals in the presence of an intact intrinsic pathway of coagulation," Thrombosis and Haemostasis, vol. 80, no. 5, pp. 829-835, 1998.

[46] P. Klement, P. Liao, and L. Bajzar, "A novel approach to arterial thrombolysis," Blood, vol. 94, no. 8, pp. 2735-2743, 1999. 
[47] M. Nagashima, M. Werner, M. Wang et al., "An inhibitor of activated thrombin-activatable fibrinolysis inhibitor potentiates tissue-type plasminogen activator-induced thrombolysis in a rabbit jugular vein thrombolysis model," Thrombosis Research, vol. 98, no. 4, pp. 333-342, 2000.

[48] L. O. Mosnier, B. V. Zlokovic, and J. H. Griffin, "The cytoprotectiveprotein C pathway," Blood, vol. 109, pp. 31613172, 2007.

[49] K. W. Muir, C. J. Weir, W. Alwan, I. B. Squire, and K. R. Lees, "C-reactive protein and outcome after ischemic stroke," Stroke, vol. 30, no. 5, pp. 981-985, 1999.

[50] D. E. Joyce, L. Gelbert, A. Ciaccia, B. DeHoff, and B. W. Grinnell, "Gene expression profile of antithrombotic protein $\mathrm{C}$ defines new mechanisms modulating inflammation and apoptosis," Journal of Biological Chemistry, vol. 276, no. 14, pp. 11199-11203, 2001.

[51] T. Cheng, D. Liu, J. H. Griffin et al., "Activated protein C blocks p53-mediated apoptosis in ischemic human brain endothelium and is neuroprotective," Nature Medicine, vol. 9, no. 3, pp. 338-342, 2003.

[52] T. Cheng, A. L. Petraglia, Z. Li et al., "Activated protein C inhibits tissue plasminogen activator-induced brain hemorrhage," Nature Medicine, vol. 12, no. 11, pp. 1278-1285, 2006.

[53] J. H. Griffin, J. A. Fernandez, L. O. Mosnier et al., "The promise of protein C," Blood Cells, Molecules, and Diseases, vol. 36, no. 2, pp. 211-216, 2006.

[54] G. R. Bernard, J.-L. Vincent, P.-F. Laterre et al., "Efficacy and safety of recombinant human activated protein $\mathrm{C}$ for severe sepsis," New England Journal of Medicine, vol. 344, no. 10, pp. 699-709, 2001.

[55] R. González-Conejero, I. Fernández-Cadenas, J. A. Iniesta et al., "Role of fibrinogen levels and factor XIII V34L polymorphism in thrombolytic therapy in stroke patients," Stroke, vol. 37, no. 9, pp. 2288-2293, 2006.

[56] I. Fernandez-Cadenas, C. A. Molina, J. Alvarez-Sabín et al., "ACE gene polymorphisms influence t-PA-induced brain vessel reopening following ischemic stroke," Neuroscience Letters, vol. 398, no. 3, pp. 167-171, 2006.

[57] I. Fernandez-Cadenas, J. Alvarez-Sabin, M. Ribo et al., "Influence of thrombin-activatable fibrinolysis inhibitor and plasminogen activator inhibitor-1 gene polymorphisms on tissue-type plasminogen activator-induced recanalization in ischemic stroke patients," Journal of Thrombosis and Haemostasis, vol. 5, no. 9, pp. 1862-1868, 2007.

[58] J. Martí-Fàbregas, M. Borrell, D. Cocho et al., "Hemostatic markers of recanalization in patients with ischemic stroke treated with rt-PA," Neurology, vol. 65, no. 3, pp. 366-370, 2005.

[59] J. Martí-Fàbregas, M. Borrell, D. Cocho et al., "Change in hemostatic markers after recombinant tissue-type plasminogen activator is not associated with the chance of recanalization," Stroke, vol. 39, no. 1, pp. 234-236, 2008.

[60] E. Di Cera, “Thrombin,” Molecular Aspects of Medicine, vol. 29, no. 4, pp. 203-254, 2008.

[61] D. Tanne, R. F. Macko, Y. Lin, B. C. Tilley, and S. R. Levine, "Hemostatic activation and outcome after recombinant tissue plasminogen activator therapy for acute ischemic stroke," Stroke, vol. 37, no. 7, pp. 1798-1804, 2006.

[62] C. A. Molina, J. Montaner, S. Abilleira et al., "Time course of tissue plasminogen activator-induced recanalization in acute cardioembolic stroke: a case-control study," Stroke, vol. 32, no. 12, pp. 2821-2827, 2001.

[63] A. A. Kanner, N. Marchi, V. Fazio et al., "Serum S100 $\beta$ : a noninvasive marker of blood-brain barrier function and brain lesions," Cancer, vol. 97, no. 11, pp. 2806-2813, 2003.

[64] R. Donato, "Intracellular and extracellular roles of S100 proteins," Microscopy Research and Technique, vol. 60, no. 6, pp. 540-551, 2003.

[65] M. Rodríguez-Yañez, M. Castellanos, M. Blanco et al., "Microand macroalbuminuria predict hemorrhagic transformation in acute ischemic stroke," Neurology, vol. 67, no. 7, pp. 11721177, 2006.

[66] A. K. Daly, "Genome-wide association studies in pharmacogenomics," Nature Reviews Genetics, vol. 11, no. 4, pp. 241-246, 2010.

[67] Z. Valnickova and J. J. Enghild, "Human procarboxypeptidase $\mathrm{U}$, or thrombin-activable fibrinolysis inhibitor, is a substrate for transglutaminases: evidence for transglutaminasecatalyzed cross-linking to fibrin," Journal of Biological Chemistry, vol. 273, no. 42, pp. 27220-27224, 1998.

[68] R. A. S. Ariens, H. Philippou, C. Nagaswami, J. W. Weisel, D. A. Lane, and P. J. Grant, "The factor XIII V34L polymorphism accelerates thrombin activation of factor XIII affects crosslinked fibrin structure," Blood, vol. 96, no. 3, pp. 988-995, 2000 .

[69] A. J. Catto, H. P. Kohler, J. Coore, M. W. Mansfield, M. H. Stickland, and P. J. Grant, "Association of a common polymorphism in the factor XIII gene with venous thrombosis," Blood, vol. 93, no. 3, pp. 906-908, 1999.

[70] V. S. Hancer, R. Diz-Kucukkaya, A. K. Bilge et al., "The association between factor XIII Val34Leu polymorphism and early myocardial infarction," Circulation Journal, vol. 70, no. 3 , pp. 239-242, 2006.

[71] I. Canavy, M. Henry, P. E. Morange et al., "Genetic polymorphisms and coronary artery disease in the south of France," Thrombosis and Haemostasis, vol. 83, no. 2, pp. 212-216, 2000.

[72] J. Corral, R. González-Conejero, J. A. Iniesta, J. Rivera, C. Martínez, and V. Vicente, "The FXIII Val34Leu polymorphism in venous and arterial thromboembolism," Haematologica, vol. 85, no. 3, pp. 293-297, 2000.

[73] A. J. Catto, H. P. Kohler, S. Bannan, M. Stickland, A. Carter, and P. J. Grant, "Factor XIII Val 34 Leu: a novel association with primary intracerebral hemorrhage," Stroke, vol. 29, no. 4, pp. 813-816, 1998.

[74] A. P. Reiner, S. M. Schwartz, M. B. Frank et al., "Polymorphisms of coagulation factor XIII subunit A and risk of nonfatal hemorrhagic stroke in young white women," Stroke, vol. 32, no. 11, pp. 2580-2585, 2001.

[75] A. Slowik, T. Dziedzic, J. Pera, D. A. Figlewicz, and A. Szczudlik, "Coagulation factor XIII Val34Leu polymorphism in patients with small vessel disease or primary intracerebral hemorrhage," Cerebrovascular Diseases, vol. 19, no. 3, pp. 165170, 2005.

[76] B. Zhang, S. Ye, S. M. Herrmann et al., "Functional polymorphism in the regulatory region of gelatinase B gene in relation to severity of coronary atherosclerosis," Circulation, vol. 99, no. 14, pp. 1788-1794, 1999. 
[77] S. Blankenberg, H. J. Rupprecht, O. Poirier et al., "Plasma concentrations and genetic variation of matrix metalloproteinase 9 and prognosis of patients with cardiovascular disease," Circulation, vol. 107, no. 12, pp. 1579-1585, 2003.

[78] T. L. Medley, T. J. Cole, A. M. Dart, C. D. Gatzka, and B. A. Kingwell, "Matrix metalloproteinase-9 genotype influences large artery stiffness through effects on aortic gene and protein expression," Arteriosclerosis, Thrombosis, and Vascular Biology, vol. 24, no. 8, pp. 1479-1484, 2004.

[79] G. T. Jones, V. L. Phillips, E. L. Harris, J. I. Rossaak, and A. M. Van Rij, "Functional matrix metalloproteinase-9 polymorphism (C-1562T) associated with abdominal aortic aneurysm," Journal of Vascular Surgery, vol. 38, no. 6, pp. 1363-1367, 2003.

[80] J. Montaner, I. Fernandez-Cadenas, C. A. Molina et al., "Safety profile of tissue plasminogen activator treatment among stroke patients carrying a common polymorphism (C-1562T) in the promoter region of the matrix metalloproteinase- 9 gene," Stroke, vol. 34, no. 12, pp. 2851-2855, 2003.

[81] S. Domingues-Montanari, I. Fernandez-Cadenas, A. Del RioEspinola et al., "The I/D polymorphism of the ACE1 gene is not associated with ischaemic stroke in Spanish individuals," European Journal of Neurology, vol. 17, no. 11, pp. 1390-1392, 2010.

[82] B. Rigat, C. Hubert, F. Alhenc-Gelas, F. Cambien, P. Corvol, and F. Soubrier, "An insertion/deletion polymorphism in the angiotensin I-converting enzyme gene accounting for half the variance of serum enzyme levels," Journal of Clinical Investigation, vol. 86, no. 4, pp. 1343-1346, 1990.

[83] M. Margaglione, E. Grandone, G. Vecchione et al., "Plasminogen activator inhibitor-1 (PAI-1) antigen plasma levels in subjects attending a metabolic ward: relation to polymorphisms of PAI-1 and angiontensin converting enzyme (ACE) genes," Arteriosclerosis, Thrombosis, and Vascular Biology, vol. 17, no. 10, pp. 2082-2087, 1997.

[84] D. K. Kim, J. W. Kim, S. Kim et al., "Polymorphism of angiotensin converting enzyme gene is associated with circulating levels of plasminogen activator inhibitor-1," Arteriosclerosis, Thrombosis, and Vascular Biology, vol. 17, no. 11, pp. 3242-3247, 1997.

[85] Y. Okura, K. Hayashi, T. Shingu et al., "Angiotensin-converting enzyme insertion/deletion genotype is associated with the activities of plasma coagulation factor VII and X independent of triglyceride metabolism," Coronary Artery Disease, vol. 14, no. 4, pp. 285-291, 2003.

[86] I. Tkac, J. Salagovic, M. Kozarova, M. Javorsky, R. Tkacova, and I. Kalina, "Angiotensin-converting enzyme genotype, albuminuria and plasma fibrinogen in type 2 diabetes mellitus," Wiener Klinische Wochenschrift, vol. 115, no. 23, pp. 835839, 2003.

[87] G. J. Brouwers, H. L. Vos, F. W. G. Leebeek et al., "A novel, possibly functional, single nucleotide polymorphism in the coding region of the thrombin-activatable fibrinolysis inhibitor (TAFI) gene is also associated with TAFI levels," Blood, vol. 98, no. 6, pp. 1992-1993, 2001.

[88] M. Schneider, M. Boffa, R. Stewart, M. Rahman, M. Koschinsky, and M. Nesheim, "Two naturally occurring variants of TAFI (Thr-325 and Ile-325) differ substantially with respect to thermal stability and antifibrinolytic activity of the enzyme," Journal of Biological Chemistry, vol. 277, no. 2, pp. 1021-1030, 2002.
[89] S. Ye, F. R. Green, P. Y. Scarabin et al., "The 4G/5G genetic polymorphism in the promoter of the plasminogen activator inhibitor-1 (PAI-1) gene is associated with differences in plasma PAI-1 activity but not with risk of myocardial infarction in the ECTIM study," Thrombosis and Haemostasis, vol. 74, no. 3, pp. 837-841, 1995.

[90] L. A. Hindorff, S. M. Schwartz, D. S. Siscovick, B. M. Psaty, W. T. Longstreth Jr., and A. P. Reiner, "The association of PAI-1 promoter 4G/5G insertion/deletion polymorphism with myocardial infarction and stroke in young women," Journal of Cardiovascular Risk, vol. 9, no. 2, pp. 131-137, 2002.

[91] T. Hoekstra, J. M. Geleijnse, C. Kluft, E. J. Giltay, F. J. Kok, and E. G. Schouten, " $4 \mathrm{G} / 4 \mathrm{G}$ genotype of PAI-1 gene is associated with reduced risk of stroke in elderly," Stroke, vol. 34, no. 12, pp. 2822-2828, 2003.

[92] P. G. Wiklund, L. Nilsson, S. N. Ardnor et al., "Plasminogen activator inhibitor-1 4G/5G polymorphism and risk of stroke: replicated findings in two nested case-control studies based on independent cohorts," Stroke, vol. 36, no. 8, pp. 1661-1665, 2005.

[93] T. L. Barr, L. L. Latour, K. Y. Lee et al., "Blood-brain barrier disruption in humans is independently associated with increased matrix metalloproteinase-9," Stroke, vol. 41, no. 3, pp. e123-e128, 2010.

[94] E. Cuadrado, A. Rosell, N. Colomé et al., "The proteome of human brain after ischemic stroke," Journal of Neuropathology and Experimental Neurology, vol. 69, no. 11, pp. 1105-1115, 2010. 


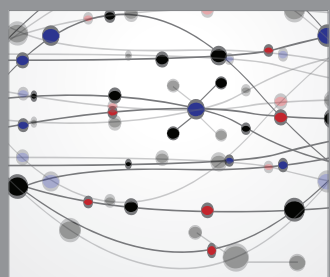

The Scientific World Journal
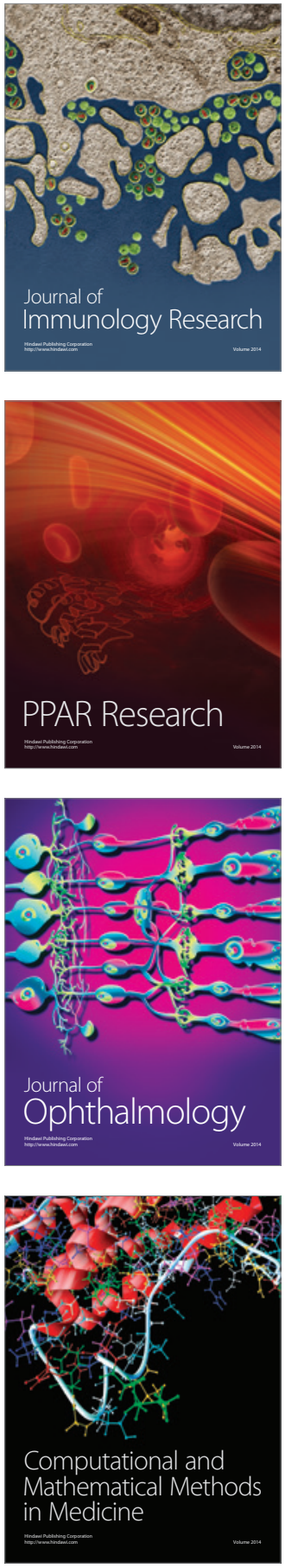

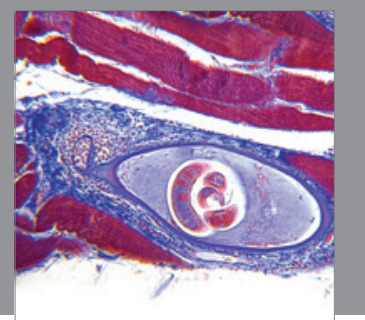

Gastroenterology

Research and Practice
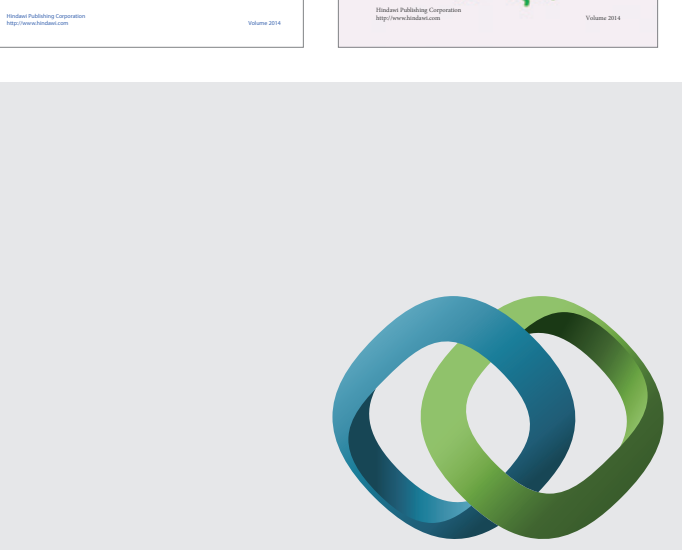

\section{Hindawi}

Submit your manuscripts at

http://www.hindawi.com
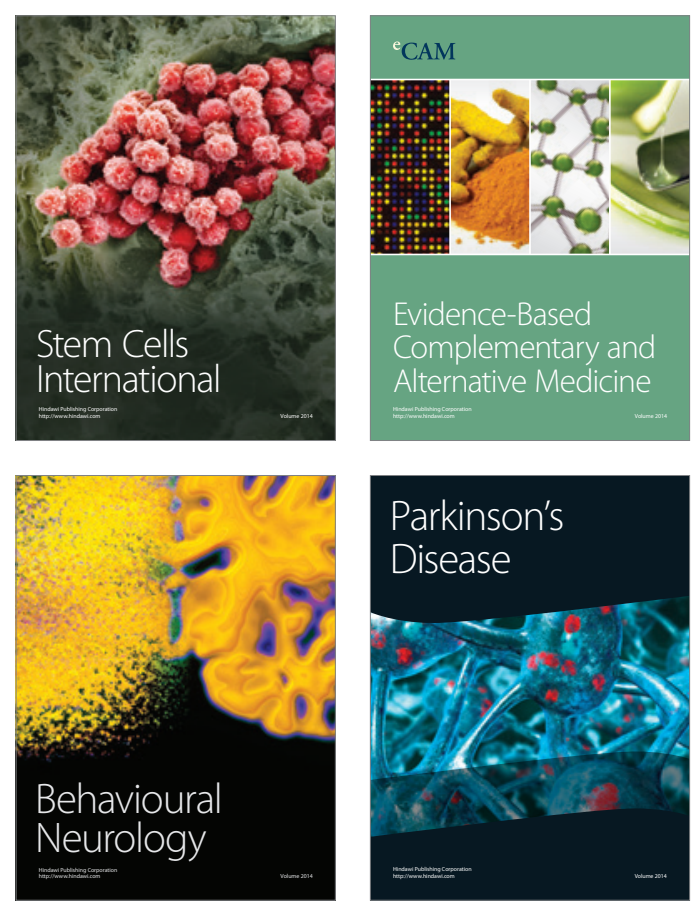

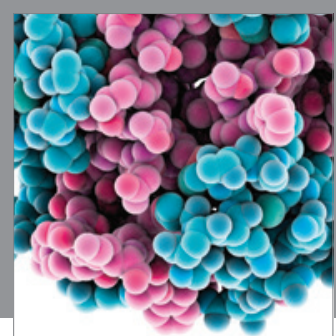

Journal of
Diabetes Research

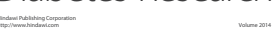

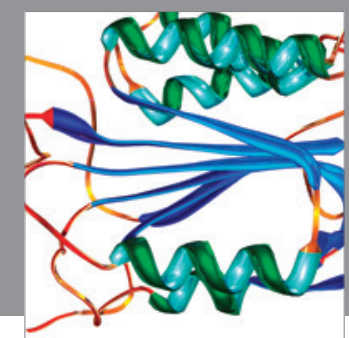

Disease Markers
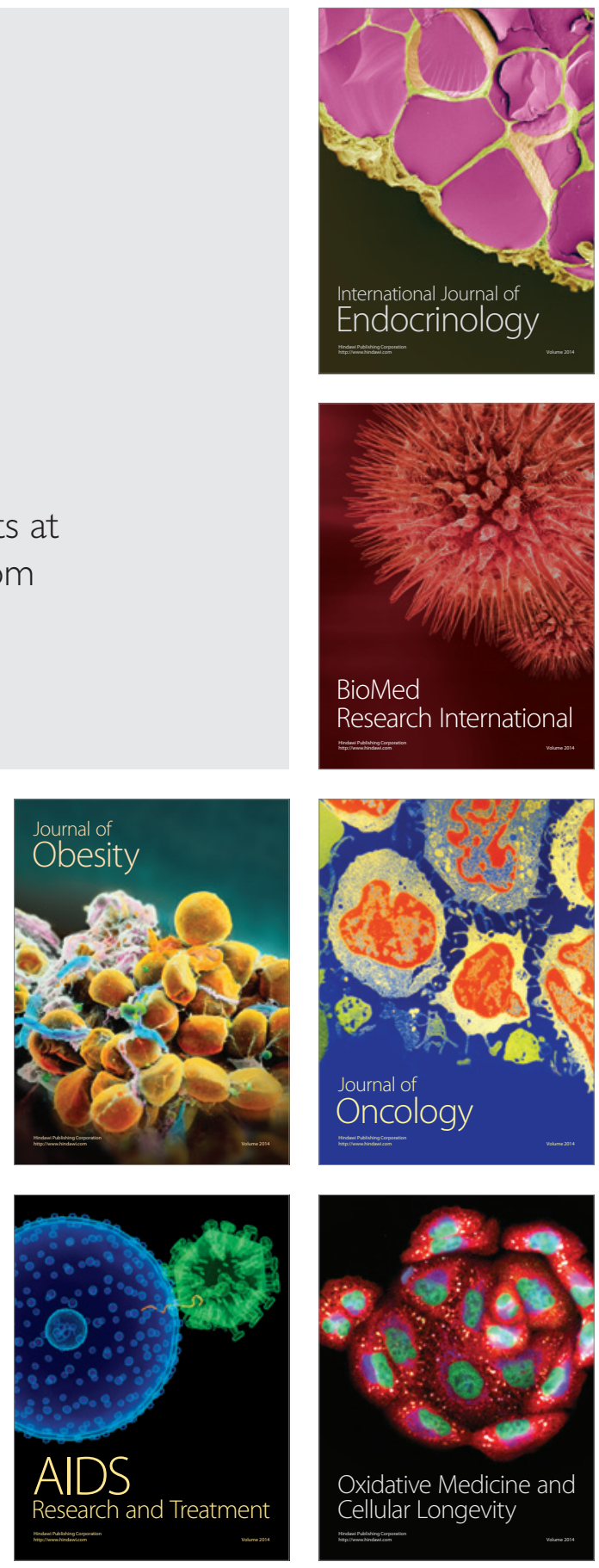